\title{
The Effectiveness of Using Corona Discharge Ozonizers for Room Disinfection
}

\author{
Smirnov Alexander A.* Ukhanova Viktoria Yu. Proshkin Yuri A. \\ Dovlatov Igor M. Sokolov Alexander V.
}

\begin{abstract}
Department of Electrical Technology, Federal Scientific Agroengineering Center VIM, Moscow, Russia
\end{abstract} *Corresponding author. Email: alexander8484@inbox.ru

\begin{abstract}
COVID-19 is considered to be a fairly new, poorly studied disease. Since there is not currently an approved and effective method of treating it, a trend to use new methods for inactivating coronavirus, which is spread mainly by airborne droplets and through contact transmission, is growing. The efficiency of using corona discharge ozonizers for disinfection of medical premises was studied. The authors developed an ozonizer that operates on undried atmospheric air, and the laboratory tests were conducted in chamber boxes to determine the effect of ozone on the overall microbial contamination. It was found that single treatments for microbiological indicators do not give a deep effect, it is necessary to apply a cyclic mode of operation of the ozonizer. The side surfaces of chamber boxes are disinfected better than horizontal ones with a difference of $11 \%$. This is due to the greater bacterial contamination of horizontal surfaces. When disinfecting premises with ozone, it is necessary to observe the safety measures, choose the correct operating modes of the ozonizer and use gas analyzers.
\end{abstract}

Keywords: coronavirus, room disinfection, ozone, air disinfection, ozonizer, COVID-19

\section{INTRODUCTION}

The SARS-CoV-2 coronavirus and caused infectious disease COVID-19 were first identified in December 2019 in Wuhan, China, which then became a major global outbreak that caused a major public health disaster around the world. It is known that SARS-CoV-2 is spread mainly by airborne droplets and through contact transmission [1]. The study [2] showed that SARS-CoV-2 residues can remain in the air as an aerosol for more than 3 hours, on cardboard for more than 24 hours, on plastic for 3 days, and on metal surfaces for up to 5 days. As long as there is no approved and effective treatment for this new disease, the trend to use new methods to disinfect premises and inactivate the virus will be growing.

In the fight against coronavirus infection, there is a positive experience of using ozone and ozone therapy in several countries, such as China, Spain, Italy and the United States. In the mid-19th century, the ozone $\left(\mathrm{O}_{3}\right)$ therapy was approved by the medical community [3] for medicinal purposes. Ozone therapy is a method that uses an oxygen-ozone-gas mixture. The biological basis of ozone therapy is the reaction of ozone with proteins, amino acids and unsaturated fatty acids, which are found in plasma and cell membranes. The oxidative degradation occurring, in this case, is expressed in the rapid accumulation of lipid peroxidation and the intensive formation of inter-protein and lipid covalent crosslinking. As a result, the ozone-induced structural modification of the membrane leads to a violation of its barrier function, in particular, to an increase in its permeability to exo- and endogenous organic compounds.

Because of the ability of ozone to completely oxidize substances, ozone therapy and ozone disinfection can be an inexpensive and safe way to eliminate SARS-CoV-2 [4]. The rationale and mechanism of action have already been clinically proven in other viral infections. In Italian hospitals, the initial reports of SIOOT (Scientific Society of Oxygen-Ozone Therapy) on the use of oxygenozone therapy in the treatment of COVID-19 were published, the results showed an improvement in patients ' clinical conditions. However, the role of ozone therapy in the management of organ damage caused by COVID-19 is worthy of further investigations [5-7].

Systemic ozone therapy, namely infusions of a physiological ozonated solution, ozone treatment of the patient's autoblood, rectal insufflations of the oxygen and ozone mixture, drinking the ozonated water, help to prevent or stop the development of a viral infection in the body. In cases of complications, such as atypical pneumonia, the effectiveness of standard treatment measures increases. Ozone is also effective when used to disinfect rooms and human skin [8].

It is known that ozone exposure has a deeper bactericidal effect compared to the use of ultraviolet (UV) irradiation (Table 1), which is explained by the direct spread of radiation and its lower energy. Ozone is distributed in the processed volume not only by convection but also by diffusion, penetrating the places inaccessible to UV radiation. The use of ozone for disinfection provides an increase in processing efficiency and environmental 
cleanliness of the process, as well as it gives a significant economic effect compared to other methods. The versatility and high efficiency of ozone exposure to microorganisms lead to wider use of ozone for sanitary purposes and improving the air environment.

Currently, when evaluating the effectiveness of a particular disinfectant, the so-called $\mathrm{C} \times \mathrm{T}$ criteria are used, i.e. the product of the concentration of the reagent for the duration of action. It can be said that INACTIVATION $=$ Concentration $\cdot$ Exposure time.
Table 2 shows the modes of exposure to ozone for the destruction of microorganisms in various environments, the time specified for $100 \%$ inactivation [9]. The effectiveness of ozone exposure to microorganisms can be represented in descending order as a series: viruses bacteria - mould - fungi - spores.

The purpose of this work is to study the effectiveness of using corona discharge ozonizers for medical premises disinfection.

Table 1 Comparison of the effectiveness of the disinfection of biological sites [9]

\begin{tabular}{|l|c|c|c|c|c|}
\hline \multicolumn{2}{|c|}{ Species of microorganisms } & \multicolumn{5}{c|}{ The effectiveness of disinfection methods } \\
\hline & $\mathrm{Cl}_{2}$ & $\mathrm{ClO}_{2}$ & $\mathrm{NH}_{2} \mathbf{C l}$ & $\mathrm{O}_{3}$ & UV-radiation \\
\hline Bacteria & +++ & +++ & ++ & +++ & ++ \\
\hline Viruses & ++ & +++ & + & +++ & +++ \\
\hline Protozoa & + & + & + & ++ & + \\
\hline
\end{tabular}

Symbols: + insufficient; ++ satisfactory; +++ good.

Table 2 The modes of exposure to ozone for the elimination of microorganisms in various media

\begin{tabular}{|c|c|c|c|c|}
\hline \multirow[t]{2}{*}{ Microflora } & \multirow{2}{*}{$\begin{array}{c}\text { Threshold } \\
\text { sensitivity, mg/l }\end{array}$} & \multicolumn{2}{|c|}{ Ozone concentration, mg/l } & \multirow[t]{2}{*}{ Time, min } \\
\hline & & Air & Water & \\
\hline Viruses & 0.0002 & 0.2 & - & 60 \\
\hline Fungi & & - & 1.5 & 120 \\
\hline Mold & 0.03 & 15 & - & 20 \\
\hline Staphylococci & & - & - & 60 \\
\hline Lactic-acid bacteria & 0.03 & 1.0 & 12 & $10-15$ \\
\hline Colon bacillus & & - & 20 & 10 \\
\hline Dysentery (No. 1402 Flexner) & 0.002 & 20 & 0.3 & 20 \\
\hline
\end{tabular}

\section{METHODS AND MATERIALS}

As a source of ozone, the OP-5 ozonizer developed by the authors was used (Figure 1), which operates on undried atmospheric air, which is important when using it in medical facilities [10]. The research has been able to determine the factors that affect the output of ozone and develop discharge elements that operate at voltages of $15-30 \mathrm{kV}$. At the same time, the discharge elements are structurally simple and reliable in operation. The principle of operation of this ozonizer is based on the formation of ozone in the corona discharge, while its operation is allowed in the recycling mode. The ozonizer has a built-in timer that provides operation in the cyclic and single-mode in the following time range -15 and 30 minutes, $1,2,4,8$ and 16 hours, and it has a remote control and monitoring panel connected to the generator by cable. The ozone capacity is $0.5-5 \mathrm{~g} / \mathrm{h}$, the air capacity is $140-500 \mathrm{~m}^{3} / \mathrm{h}$, the power consumption is 100-250 W (depending on the performance), the power supply-single-phase network is $50 \mathrm{~Hz}, 220 \mathrm{~V}$. High-performance fans, when the ozonizer is turned on, allow quickly raising the concentration of ozone. The high speed of the ozone-air mixture movement contributes to a more efficient flow of it and penetration to the treated surfaces. The choice of the operating mode of the ozonizer was made depending on the volume of the room according to the previously developed method [11]. 


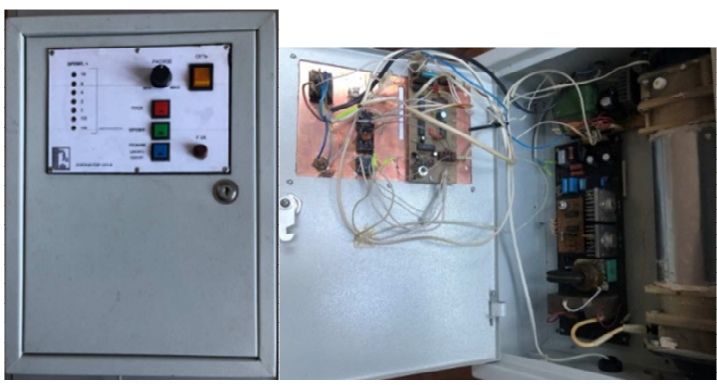

Figure 1 OP-5 corona discharge ozonizer

The experimental studies were conducted in chamber boxes with a volume of 15,90 and $250 \mathrm{~m}^{3}$ at an air temperature of $18-24{ }^{\circ} \mathrm{C}$. The concentration of ozone in the air was determined using the Cyclone 5.41 gas analyzer. The influence of ozone on the total microbial contamination was studied. Air samples were collected by the method of precipitation on Petri dishes with the media: meat-peptone agar (MPA), salt MPA, Endo's medium and Czapek's medium for 5 minutes from 10 litres of air at three points diagonally. The crops were grown in a thermostat at a temperature of $37^{\circ} \mathrm{C}$ for $2-5$ days, counting the grown colonies and calculating $1 \mathrm{~m}^{3}$ of air. Static processing of the obtained results was performed by the Student Method with the determination of the arithmetic mean and the mean square deviation.

\section{RESULTS}

When conducting laboratory tests in chamber boxes, it was found that single treatments, according to microbiological indicators, do not give a deep effect. Only after 5-6 treatments a stable effect on disinfection is obtained. This can be explained by the fact that a significant part of the ozone is sorbed on the enclosing surfaces, is spent on the oxidation of organic matter in the air and on the surfaces of the room, and is also removed by exhaust ventilation. Table 2 shows the results of tests in boxes with a volume of 15 and $90 \mathrm{~m}^{3}$. From the test results, it follows that a stable and deep decontamination effect is achieved only with regular use of ozone for disinfection treatment.

The possibility of using a cyclic mode of operation of the ozonizer for processing was also experimentally tested. This mode can be applied in cases where it is undesirable to increase the concentration of ozone in the treated area because of the equipment placed in it, for example, electrical or electronic. For example, in medical institutions, when treating wards, dressings, surgical and other premises, the concentration of ozone above $5 \mathrm{mg} / \mathrm{m}^{3}$ can not be exceeded, because of the high probability of ozone leakage into the ventilation system [12]. Figure 2 shows the change in ozone concentration over time in cyclic mode Operation/Pause - 15/15 min. As can be seen from the presented dependence, there is a tendency to increase the concentration of ozone in this mode of operation. With an increase in the duration of the pause, this trend will be overcome by a greater degree of ozone decomposition.

However, different room surfaces are treated differently (Table 4). Thus, the side surfaces are treated better than the floor. This can be explained by both the greater bacterial contamination of horizontal surfaces and the lower impact of the treating flow on the floor surface.

Table 3 The effect of the number of treatments on reducing the microflora content in the indoor air

\begin{tabular}{|c|c|c|c|c|c|}
\hline \multirow[t]{3}{*}{ Treating options } & \multirow{3}{*}{$\begin{array}{l}\text { Treating } \\
\text { frequency }\end{array}$} & \multicolumn{4}{|c|}{ Contamination, CFU/m ${ }^{3}$} \\
\hline & & \multicolumn{2}{|c|}{ Before treatment } & \multicolumn{2}{|c|}{ After treatment } \\
\hline & & Total & Including mould & Total & Including mould \\
\hline \multirow{6}{*}{$\begin{array}{l}\text { Box volume } 15 \mathrm{~m}^{3} \text {, exposure } \\
\text { for } 1 \mathrm{~h} \text {, the performance of the } \\
\text { ozone generator is } 1 \mathrm{~g} / \mathrm{h}\end{array}$} & 1 & 400 & 20 & 130 & 10 \\
\hline & 2 & 320 & 0 & 90 & 0 \\
\hline & 3 & 200 & 20 & 80 & 0 \\
\hline & 4 & 200 & 0 & 80 & 0 \\
\hline & 5 & 400 & 0 & 50 & 0 \\
\hline & 6 & 300 & 0 & 20 & 0 \\
\hline \multirow{5}{*}{$\begin{array}{l}\text { Box volume } 90 \mathrm{~m}^{3} \text {, exposure } \\
\text { for } 4 \mathrm{~h} \text {, the performance of the } \\
\text { ozone generator is } 1 \mathrm{~g} / \mathrm{h}\end{array}$} & 1 & 170 & 10 & 30 & 0 \\
\hline & 2 & 100 & 0 & 20 & 0 \\
\hline & 3 & 130 & 0 & 10 & 0 \\
\hline & 4 & 50 & 0 & 7 & 0 \\
\hline & 5 & 80 & 0 & 1 & 0 \\
\hline
\end{tabular}


Table 4 The efficiency of treating various surfaces of the room with a volume of $250 \mathrm{~m}^{3}$, treating time -4 hours

\begin{tabular}{|c|c|c|c|c|}
\hline \multirow[t]{2}{*}{ Treating facility } & \multirow{2}{*}{$\begin{array}{c}\text { Ozone oncentration, } \\
\mathrm{mg} / \mathrm{m}^{3}\end{array}$} & \multicolumn{2}{|c|}{ Number of microflora, $1 / \mathrm{cm}^{2}$} & \multirow{2}{*}{$\begin{array}{l}\text { The effect of } \\
\text { treatment, \% }\end{array}$} \\
\hline & & Before treatment & After treatment & \\
\hline Wall & 1.6 & $1 \cdot 10^{7}$ & - & 100 \\
\hline Floor & 1.6 & $44 \cdot 10^{7}$ & $5 \cdot 10^{7}$ & 88.7 \\
\hline
\end{tabular}

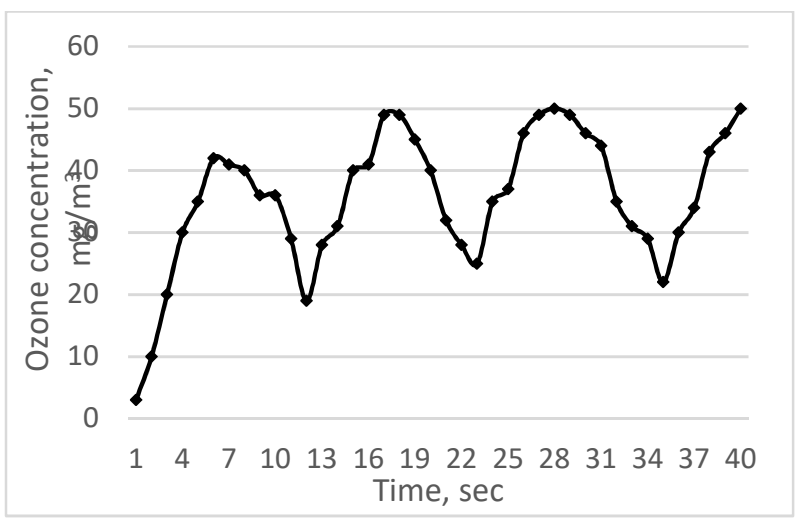

Figure 2 The changes in ozone concentration over time during cyclic operation

Taking into account the lower threshold sensitivity of viruses to ozone compared to bacteria (Table 2), it can be assumed that the studied modes of indoor ozonation will also be effective for inactivating coronaviruses. Based on experimental data, it can be recommended formula for calculating the required performance of the ozonizer: $G=\frac{K C V\left(1-K_{3}\right)}{T}$

where $G-$ the performance of the ozonizer, $\mathrm{g} / \mathrm{h} ; K-$ the rate of ozone consumption, $C$ - the concentration of ozone, $\mathrm{mg} / \mathrm{m}^{3}, V$ - the volume of the room, $\mathrm{m}^{3} ; K_{z}$ - the filling factor (the ratio of the volume of the processing object and the volume of the chamber), $T$ - treating time, $h$.

When operating the ozonizer in the mode of recirculating the ozone-air mixture, regardless of where the ozonizer is located, inside or outside, there is practically no pressure difference between the volume and the media and it means that the probability of ozone leakage from the treated volume is minimal. This significantly increases the safety of personnel when operating ozonizer equipment [13]. Also, the high speed of air movement in the processed volume intensifies the process of inactivation of microflora.

However, when using ozone, the safety measures must be observed, since ozone belongs to the first hazard class, the maximum permissible concentration (MPC) of ozone in the air of the working area is $0.1 \mathrm{mg} / \mathrm{m}^{3}$, and the maximum single MPC of ozone in the atmospheric air is $0.16 \mathrm{mg} / \mathrm{m}^{3}$. At high concentrations, ozone has an intense toxic effect [13]. It was found that the half-life of ozone is 8 minutes, using the previously developed method, the necessary time of ozone decay is calculated after switching off the ozonizer to the MPC level [14]. Also, appropriate gas analyzers must be used to monitor the ozone content in the air.

\section{CONCLUSION}

Ozonation can be considered as an effective method of disinfection of medical premises, including for inactivation of viruses. It is established that the single treatments, according to microbiological indicators, do not give a deep effect, it is necessary to apply a cyclic mode of operation of the ozonizer. The side surfaces are disinfected better than the horizontal ones with a difference of $11 \%$, this is due to the greater bacterial contamination of the horizontal surfaces. When disinfecting premises with ozone, it is necessary to observe the safety measures, choose the correct operating modes of the ozonizer and use gas analyzers.

\section{REFERENCES}

[1] J. Liu, X. Liao, S. Qian et al., Community Transmission of Severe Acute Respiratory Syndrome Coronavirus 2, Emerging Infectious Diseases, 26(6) (2020) 1320-1323, Shenzhen, China. DOI: 10.3201/eid2606.200239

[2] N. van Doremalen, T. Bushmaker et al., Aerosol and Surface Stability of SARS-CoV-2 as Compared with SARS-CoV-1, New Engl. Jo. of Med. 1 (2020) 1564-1567. DOI: 10.1056/NEJMc2004973

[3] A. Elvis, J. Ekta, Ozone Therapy: A Clinical Review, J. of Natural Sci., Biol. and Med. 66(2(1)) (2011) 15. DOI: $10.4103 / 0976-9668.82319$

[4] R. Rowen, H. Robins, A Plausible "Penny" Costing Effective Treatment for Corona Virus Ozone Therapy, J. Infect Dis Epidemiol 6 (2020) 113. DOI: 10.23937/2474-3658/1510113

[5] G. Martínez-Sánchez, A. Schwartz, V. Di Donna, Potential Cytoprotective Activity of Ozone Therapy in SARS-CoV-2/COVID-19, Antioxidants 389(9) (2020). DOI: 10.3390/antiox9050389

[6] L. Valdenassi, M. Franzini, G. Ricevuti et al., Potential Mechanisms by Which the Oxygen-Ozone (O2-O3) Therapy Could Contribute to the Treatment 
Against the Coronavirus COVID-19, Eur. Rev. Med. Pharmacol. Sci. 24(8) (2020) 4059-4061. DOI: 10.26355/eurrev_202004_20976

[7] S. Hajebrahimi, N. Taleschian-Tabrizi, S. Karkon Shayan, A. Tavassoli, Using Ozone Therapy as an Option for Treatment of COVID-19, Patients: A scoping review Running title: Ozone Therapy for COVID-19. DOI: 10.22541/au.158802287.70368740

[8] Texas Right to Know Calls on the US to Consider COVID-19 Ozone Therapy After It Shows Promise in Italy. Retrieved from: https://www. prnewswire.com/news-releases/texas-right-to-knowcalls-on-us-to-consider-covid-19-ozone-therapyafter-it-shows-promise-in-italy-301034221.html, accessed 30.05.2020.

[9] M.P. Butko, V.S. Frolov, Ozone: Synthesis and Its Application, GNU VNIIVSGE, Moscow, 2010, 57 p.

[10] I.M. Dovlatov, A.A. Smirnov, D.Yu. Pavkin, W.P. Zaikin, Technology and Means for Improving the Microclimate of Livestock Premises, Bull. NGIEI 4(107) (2020) 34-43.

[11] A. Smirnov, V. Ukhanova, I.G. Ershova, B. Koshoeva, Optimization of Processing Modes of Disinfection of Vegetable Storehouses With the Use of Ozone, Handbook of Research on Smart Computing for Renewable Energy and AgroEngineering, 2020., pp. 27-51. DOI: 10.4018/978-17998-1216-6.ch002

[12] S.V. Yakimov, G.V. Makarskaya, S.V. Tarskih et al., To the Question of the Safety of Gaseous Ozone in the Clinic, In the collection: Actual Issues of Modern Surgery, 2018, pp. 363-366.

[13] I.I. Polosin, D.V. Lobanov, Recovery of Air Environment of a Room by Air Ozonation and Air Ionization, Sci. Bull. of the Voronezh State Univer. of Architect. and Civil Engineer. (1) (2012) 15-20.

[14] A.F. Pershin, K.V. Bogdanov, A.A. Smirnov, To the issue of safe operation of disinfection chambers using ozone, Innovat. in agricult. 1 (2012) 50-54. 